\title{
Evolution Model of Friendship Network and Bully/Victim for Adolescence
}

\author{
Chyi-In $\mathrm{Wu}^{1}$ and Hsieh-Hua Yang ${ }^{2+}$ \\ ${ }^{1}$ Institute of Sociology, Academia Sinica, Taipei 11529, Taiwan \\ ${ }^{2}$ Oriental Institute of Technology, New Taipei City 22061, Taiwan
}

\begin{abstract}
Social network formation is an evolution process. Many behavioral factors have been proposed to account for friendship network stability. Bullying behavior occurs within the interaction process and causes another person injury as a victim. It may violate friendship. van Duijn et al. (2003) proposed the concept of visible and invisible variables to explain how changes in the network structure. The objective of the research is to construct the evolution model of friendship network and bully/victim, and scrutinize the visible or invisible trait of bullying and the experience of victimization. The program SIENA was applied to estimate the models for the evolution of social networks according to the dynamic actor-oriented model. The result showed that gender is a robust visible variable, while bullying and victimization play visible and invisible role to exert effect on friendship network evolution. The implication is discussed.
\end{abstract}

Keywords: evolution model, friendship network, adolescence, bullying, victimization

\section{Introduction}

Many behavioral factors have been proposed to account for friendship network stability. Poulin and Chan [1] grouped these factors into internalizing and externalizing behaviors. The experience of peer victimization is one of the internalizing behaviors which may be associated with friendship stability. And aggression is pertaining to the externalizing behavior which may lead to friendship rejection or isolation.

Bullying is a pervasive problem in school. Research has indicated that peer are present in approximately $85 \%$ of school bullying episodes [2] and various participant roles have been identified [3]. The prevalence rate was $10.3 \%$ for bullying others, and $11.3 \%$ for being bullied [4]. Experiences of victims would have great impact on their peer relations. A study showed that victimized children experience difficulty forming new friendships [5]. Children who lost friendships became more victimized over time, whereas those who gained friendships over time became less victimized [6]. And the children who maintain stable friendships displayed low levels of victimization [6].

Social network analysis is uniquely suited for measuring and understanding the behavior of peers because it provides a formal means for "mapping" friendships and measuring properties of those friendships [7]. McPherson, Smith-Lovin and Cook [8] proposed a homophily principle to explain the network autocorrelation, which stands for the argument that it is easier or more rewarding for an actor to interact with a similar other than with a dissimilar other.

It is clear that the friendships of adolescents are based on propinquity in the beginning; then will be developed by common activities. Behaviors and friendship network will interact with each other. Focus theory posits that regular, sustained contact centered on an activity increases the likelihood that friendships will develop [9]. van Duijn et al. [10] develop a theory to explain how changes in the network structure. The theory posits that proximity plays a dominant role in the formation of networks, visible similarity plays a role

\footnotetext{
+ Corresponding author. Tel.: 886-277380145.

E-mail address: yansnow@gmail.com.
} 
in the beginning of the friendship development process, and invisible similarity will have effect at later stages of the friendship development. In this research, the visible or invisible trait of bullying and the experience of victimization are discussed in the model of friendship evolution and bully/victim.

\section{Method}

Data were collected by the research project "Luminous Shine and Dark Shadow: The Duality of Late Adolescents to Early Adults' Friendship Networks" sponsored by the Academia Sinica in Taiwan. In this study, the analysis were run on 175 high school students of 93 boys and 82 girls.

Panel data was collected 4 waves during a semester from Sep. 2008 to Jan. 2009. Sociometric data were collected by having each student nominate up to 16 intimate classmates. Bullying behavior and victimization was measured in the beginning of the semester.

Five bullying behaviors were measured by asking "During this semester, have you ever hit (attack, push, extort, threat) someone?" If there is at least one violent behavior, the bullying is coded as 1 , else is 0 . Victimization was measured by asking "have you ever been attacked or threatened during this semester?" The variable victim is coded as 1 if the answer is yes.

The program SIENA (Simulation Investigation for Empirical Network Analysis) was applied to estimate the models for the evolution of social networks according to the dynamic actor-oriented model of Snijders [11]-[13]. For the estimation, sociometric data was transformed into adjacency matrices. Individual variables include gender and bully/victim. Gender was coded as 1 for boys, and 2 for girls.

\section{Result}

The program SIENA was applied to construct the evolution model of friendship networks and bully/victim behavior. The participants were 93 boys and 82 girls. The frequency of bully and victim are presented as table 1 . The friendship network evolution model is presented as table 2 .

TABLE I: DESCRIPTION OF PARTICIPANTS

\begin{tabular}{|l|r|r|c|}
\hline Variable & $\mathrm{N}$ & $\%$ & chi-square \\
\hline Bully & & & $14.23^{* * *}$ \\
\hline Boy $(\mathrm{n}=93)$ & 69 & 74.2 & \\
\hline Girl (n=82) & 38 & 46.3 & $16.08^{* * *}$ \\
\hline Victimization & & & \\
\hline Boy $(\mathrm{n}=93)$ & 33 & 35.5 & \\
\hline girl $(\mathrm{n}=82)$ & 8 & 9.8 & \\
\hline
\end{tabular}

TABLE I: EVOLUTION MODEL

\begin{tabular}{|c|c|c|c|}
\hline Variable & Estimate (se) & $\underline{\text { Estimate }}$ & Estimate (se) \\
\hline Rate & $7.00(0.27)$ & $5.36(0.24)$ & $5.54(0.24)$ \\
\hline Outdegree effect & $-2.06(0.06)^{*}$ & $-1.91(0.07)^{*}$ & $-2.20(0.07)^{*}$ \\
\hline Reciprocity & $0.94(0.09)^{*}$ & $1.20(0.10)^{*}$ & $1.36(0.10)^{*}$ \\
\hline Transitive triplets & $0.11(0.01)^{*}$ & $1.13(0.01)^{*}$ & $0.11(0.01)^{*}$ \\
\hline Gender similarity & $0.37(0.08)^{*}$ & $0.39(0.08)^{*}$ & $0.45(0.10)^{*}$ \\
\hline Bully alter & $0.09(0.09)$ & $0.34(0.09) *$ & $0.26(0.10)^{*}$ \\
\hline Bully ego & $-0.13(0.10)$ & $0.15(0.10)$ & $-0.15(0.11)$ \\
\hline Bully similarity & $-0.1(0.08)$ & $0.09(0.09)$ & $-0.05(0.10)$ \\
\hline Victim alter & $-0.26(0.11)^{*}$ & $-0.13(0.11)$ & $-0.41(0.13)^{*}$ \\
\hline Victim ego & $-0.44(0.13)^{*}$ & $0.24(0.12)$ & $0.05(0.13)$ \\
\hline Victim similarity & $-0.03(0.10)$ & $-0.02(0.10)$ & $-0.18(0.11)$ \\
\hline
\end{tabular}

The frequency of boys was higher than girls for both bully and victim. Within 175 students, about 3 quarters of the boys and half of the girls had the bullying behaviour of hit, attack, push, extort, threat, or push on others in the first semester. The frequency of victimization was one third for boys and nearly $10 \%$ for girls. 
The program SIENA was run on the 175 students. The parameter estimates separately for period w1-2, w2-3, and w3-4. The rate parameter indicates that the estimated number of changes per actor between two observations. The parameter estimates of rate function obtained for each period, with approximate confidence intervals extending two standard errors to either side of the parameter estimate. At the first observation, the rate parameter was the highest.

The standard errors can be used to test the parameters. The weights can be tested by t-statistics, defined as estimate divided by its standard error. If it is larger than 2 in absolute value, the estimate is significant at the 0.05 significance level. In table 2 , there is strong evidence for the effect of density, reciprocity and transitive triplets. The reciprocity effect indicates a preference for reciprocating relationships. The transitive effect indicates a preference for being friends with friends' friends.

The effect of gender similarity was significant during all the waves. The positive parameter implies that the participants prefer ties to others with same gender.

The effect of bully and victim is presented as table 2 . The effect of bully alter is significant for w2-3, and w3-4. The positive parameter of bully alter implies that the actors of higher value of bully are more popular. The negative parameter of bully alter implies that the actors of higher value of bully are less popular.

The effect of victim alter is significant for w1-2, and w3-4. The negative parameter of victim alter means that the actors with higher value of victim are less popular. The effect of victim ego is significant for w1-2. The negative parameter of victim ego implies that the actors with higher value of victim nominate had fewer friends. There is not significant effect of bully similarity and victim similarity.

\section{Discussion and Conclusion}

Positive parameter of gender similarity implies the tendency of preference to make same-sex friends. Gender is a visible variable and exerts effect in the beginning of friendship formation. Further, gender is a robust visible variable and keeps the homophily effect till the end of observation.

Bullying behaviour can be observed and treated as a visible variable. The result may be explained by van Duijn's theory. The visible bullying behavior has effect in the beginning of friendship development. The significant positive parameter of bully alter means the students prefer to nominate friends who have more bullying behavior. The initiation of friendship needs social skill or communication ability. It is supposed that the adolescents use bullying behavior to communicate with others. It is suggested that girls have better interpersonal skills than boys. Girls language is relatively more likely to be collaborative and affiliative [14], [15], while boys' language is relatively more assertive, controlling, and competitive and incorporates more demands [16]. Researcher indicated bullying is a form of proactive aggression intended to achieve, demonstrate, or maintain social dominance [17]. The higher frequency of boys' bullying behaviours may be explained by the deficit of interpersonal skills.

The experience of victimization is an internalizing behavior and treated as invisible variable. According to van Duijn's theory, the effect of victimization should be significant in later stage of friendship evolution. Our findings showed illegibility.

The purpose of this article is testing the effect of bullying and victimization on friendship network evolution. Theoretically, visible similarity plays a role in the beginning of the friendship development process, and invisible similarity will have effect at later stages of the friendship development. The result showed that gender is a visible variable and play a role in the beginning and during all the observing stages. In conclusion, the result supports the theory proposed by van Duijn.

\section{Acknowledgment}

The work is supported by the National Science Council (NSC97-2410-H-001-098-MY3).

\section{References}

[1] F. Poulin, and A. Chan, "Friendship stability and change in childhood and adolescence," Dev. Rev., vol. 30, pp. 257-272, 2010. 
[2] W. M. Craig, and D. J. Pepler, "Observations of bullying and victimization in the school yard, Can. J. School Psychol., vol. 13, pp. 41-59, 1997

[3] C. Salmivalli, K. Lagerspetz, K. Bjorkqvist, K. Osterman, and A. Kaukiainen, "Bullying as a group process: Participant roles and their relations to social status within the group," Aggressive Behav., vol. 22, pp. 1-15, 1996.

[4] C. Currie, et al. (eds.), Social determinants of health and well-being among young people, Health Behavior in School-aged Children (HBSC) Study, International Report From the 2009/23010 Survey, Copenhagen, WHO Regional Office for Europe, 2012.

[5] W. E. Ellis, and L. Zarbatany, "Explaining friendship formation and friendship stability: The role of children's and friends' aggression and victimization,” Merrill Palmer Quart., vol. 53, pp. 79-104, 2007.

[6] J. C. Wojslawowicz, K. H. Rubin, K. B. Burgess, C. Booth-LaForce, and L. Rose-Krasnor, "Behavioral characteristics associated with stable and fluid best friendship patterns in middle childhood," Merrill Palmer Quart., vol. 52, pp. 671-693, 2006.

[7] S. T. Ennett, and K. E. Bauman, "Adolescent social networks: school, demographic, and longitudinal considerations," J. Adolescent Res., vol. 11, pp. 194-215, 1996.

[8] J. M. McPherson, L. Smith-Lovin, and J. M. Cook, "Birds of a feather: homophily in social networks," Annu. Rev. Sociol., vol. 27, pp. 415-444, 2001.

[9] S. L. Feld, "The focused organization of social ties,” Am. J. Sociol., vol. 86, pp. 1015-1035, 1981.

[10] M. A. J. van Duijn, E. P. H. Zeggelink, M. Huisman, F. N. Stokman, and F. W. Wasseur, "Evolution of sociology freshmen into a friendship network," J. Math. Sociol., vol. 27, pp. 153-191, 2003.

[11] T. A. B. Snijders, "Stochastic actor-oriented models for network change," J. Math. Sociol. Vol. 21, pp. 149-172, 1996. doi: https://www.stats.ox.ac.uk/ snijders/siena/SAOM.pdf.

[12] T. A. B. Snijders, "The statistical evaluation of social network dynamics," in Sociological Methodology, M. E. Sobel, M. P. Becker, Eds. Basil Blackwell, Boston, 2001.

[13] T. A. B. Snijders, C. Steglich, and M. Schweinberger, "Modeling the coevolution of networks and behavior," in Longitudinal Models in the Behavioral and Related Sciences, K. van Montfort, J. Oud, A. Satorra, Ed. Lawrence Erlbaum Associates, New Jersey. 2007.

[14] C. Leaper, "Influence and involvement in children's discourse: Age, gender, and partner effects," Child Dev., vol. 62, pp. 797-811, 1991.

[15] J. Strough, and C. A. Berg, "Goals as a mediator of gender differences in high-affiliation dyadic conversations," Dev. Psychol., vol. 36, pp. 117-125, 2000.

[16] C. Leaper, and T. Smith, “A meta-analytic review of gender variations in children's language use: Talkativeness, affiliative speech, and assertive speech," Dev. Psychol. vol. 40, pp. 993-1027, 2004.

[17] A. D. Pellegrini, "Bullies and victims in school: A review and call for research," J. Appl. Dev. Psychol., vol. 19, pp. 165-176, 1998. 